\title{
Georgian legume crop extract as an effective remedy during oral cavity soft tissue inflammation
}

\author{
Chkhikvishvili I. ${ }^{1,2}$, Mghebrishvili S. ${ }^{1}$, Kipiani Nana V. ${ }^{1}$, Barbakadze I. ${ }^{1}$, Komakhidze N. ${ }^{3}$, \\ Maminaishvili T. ${ }^{3}$, Shekiladze E. ${ }^{1}$, Japaridze S. ${ }^{1}$, Sanikidze T. ${ }^{1}$
}

${ }^{1}$ Tbilisi State Medical University, ${ }^{2}$ V. Bakhutashvili Institute of Medical Biotechnology of Tbilisi State Medical University, ${ }^{3}$ Davit Aghmashenebeli University of Georgia

Corresponding author: Tamar V. Sanikidze, $\mathrm{PhD}, \mathrm{ScD}$, professor, Department of Physics, Biophysics, Biomechanics and Informative Technologies, Tbilisi State Medical University, Vaja Pshavela av., 33, Tbilisi, 0186, Georgia.

Submission Date: November 20 ${ }^{\text {th }}, 2019$ Acceptance Date: January $23^{\text {rd }}$, 2020 Publication Date: January $31^{\text {st }}, 2020$

Citation: Chkhikvishvili I., Mghebrishvili S., Kipiani Nana V., Barbakadze I., Komakhidze N., Maminaishvili T., Shekiladze E., Japaridze S., Sanikidze T. Georgian legume crop extract as an effective remedy during oral cavity soft tissue inflammation. Functional Foods in Health and Disease 2020; 10(1): 55-64. DOI: https:/doi.org/10.31989/ffhd.v10i1.678

\begin{abstract}
Background: Recovery of dental arch defects, related to insertion of a foreign bodies into the oral cavity, and the impact of mechanical pressure, allergic-toxic effects, and the related inflammatory and degenerative processes is one of the most urgent problems in dentistry. The purpose of the study was to evaluate the efficacy of Georgian bean extract tincture as mouthwash for patients using a lever system to correct deformities of the jaw and teeth.
\end{abstract}

Methods: Twenty-eight patients (aged 12-25 years) with deformities of the jaw and teeth were studied. Patients were examined 6-8 months after the bracket system was installed, and before and after the use of tincture mouthwash for 10 days. Patients were randomly divided into 2 groups: the control group for the mouthwash used standard tincture ("Octenidol" Schulke and Mayr Germany); the patients of the experimental group used tincture made from the Georgian legume crop extracts (GLCE). Before and after the use of both types of tincture, the data were taken for calculation of Schiller Pisarev's test (SPT), Papillary-Marginal Alveolar (PMA) index, and the oral hygiene index (OHI). Saliva was collected in a glass tube without stimulation, on an empty stomach. The content of cytokines IL-1 $\beta$, IL-10 in saliva was determined by the ELISA kit.

Results: The study demonstrated significant positive clinical efficacy of the mouthwash tincture prepared from the GLCE which increases the resistance of dental tissue. This was revealed by significantly lower values of OHI, PMA index, SPT and increased content of IL-10 in saliva. 
This data indicates that tincture prepared from the Georgian legume crop extracts, which is designed to increase the stability of oral tissue, does promote an increase in resistance to the aggressive mechanical pressing.

Conclusion: Tincture from the GLCE is characterized by a much stronger anti-inflammatory effect than standard tincture "Octenidol" (Schulke and Mayr -Germany) used against inflammation of the oral cavity soft tissue. This allows us to recommend the tincture from the GLCE for the treatment and prevention of inflammatory processes in the oral cavity soft tissue.

Keywords: Georgian legumes crop extracts (GLCE), oral cavity soft tissue inflammation, Hygiene Index, PMA index, Schiller Pisarev's test.

\section{BACKGROUND}

On the modern stage of development of dentistry recovery of the dental defects are related to the insertion of the foreign body into the oral cavity, with the further complex impact (mechanical pressure, allergic-toxic effects of the oral cavity mucous tissue, inflammatory and degenerative processes) [1-3]. The prevention and correction of these harmful effects is one of the most urgent problems in dentistry [4-7].

An important role in the development of the inflammatory response in oral cavity tissues plays alteration in redox balance and immune metabolism. Scientists' attention is attracted by natural antioxidant compounds that have a protective, healing effect on a living organisms. Studies are focused on the identification of compounds with new effective pharmacological properties and the investigation of molecular mechanisms of their activity [8-16]. The importance of leguminous crops is known for human health. The beans (Phaseolus vulgaris L.) are the most common culture in Georgia and the whole world. It is supposed that the high content of the bioactive compounds in beans provides their anti-inflammatory, anti-aging, anti-tumor activity [17-20].

We studied the efficacy of mouthwash with a tincture made from Georgian bean extracts in patients wearing a lever system to correct deformities of the jaw and teeth. The purpose of the study was to evaluate the efficacy of the Georgian bean extract tincture for the mouthwash of the oral cavity of patients using a lever system to correct deformities of the jaw and teeth.

\section{MATERIALS AND METHODS}

\section{Clinical Examination of the Patients}

Twenty-eight patients (aged 12-25 years) with deformities of the jaw and teeth were studied. Clinical trials included the evaluation of subjective and objective indicators. Subjective indicators were: patients' complaints, transmitted and congenital diseases, allergic reactions to medications, socioeconomic status of the patient, nutrition and oral cavity hygiene; objective indicators of oral cavity: mouth gate condition and lips, type of teeth, tooth alignment in tooth arch, presence of tremors and distances, degree of flexion of orthopedic structures. In order to study metabolic indicators of the oral cavity, we examined the content of cytokines (IL-1 $\beta$, IL-10) in the patients' saliva. The study protocol was approved by the Ethical Committee of the David Aghmashenebeli, University of Georgia. 
All patients underwent clinical examinations according to the following scheme: examination, anamnesis assembly, objective assessment of the jaw-tooth system. Patients were examined 6-8 months after the establishment of the bracket system, before and after using the tincture for rinsing the mouth (within 10 days).

Patients were randomly divided into 2 groups: patients in the control group (14 patients) used standard tincture ("Octenidol" Schulke and Mayr-Germany) for the mouthwash; patients in the experimental group (14 patients) used tincture made from the previously investigated GLCE [16, $21,22]$. Both types of tinctures were used in a volume of $50 \mathrm{ml} 2$ times a day (rinsing was carried out for about 30 seconds). Before and after the use of both types of tincture, studies were conducted to establish the Papillary-Marginal Alveolar (PMA) index [23], the oral hygiene index (OHI) and the Schiller Pisarev's test (SPT) [24].

SPT usually is used to diagnose inflammation in patients with periodontal disease (after the treatment the oral mucosa is extracted with the following solution: Jodi puri crystallite - 1,0; Iodate pull cob - 2.0, Aq. Distill - 40.0). The severity of inflammation was determined by coloring: negative (+) (yellowish-brown), weak (++) (light brown) and positive (+++) (dark brown). During the inflammation the color of epithelium varies from light brown to pale brown; in the case of healthy periodontal tissue, the color of gum does not change.

The PMA index was evaluated according to the following codes and criteria: 0 - absence of inflammation; 1 - inflammation only on the gum (P); 2 - inflammation of the marginal gum (M); 3 - inflammation of the alveolar gland (A).

The PMA index is calculated as follows:

$$
\mathrm{PMA}=\frac{\sum P+M+A}{3 \times \mathrm{n}(\text { number of teeth })} \times 100 \%
$$

Results will be evaluated as follows: $\leq 33 \%$ - low; $34-66 \%$ - average; $\geq 67 \%$ - high.

We used the Fyodorov-Volodkin index (OHI) to study oral hygiene: the oral hygiene was determined according to the color of the vestibular surface of the teeth, 43, 42, 41, 31, 32, 33, stained with Lugol's paint. The painted surface of the tooth crown is graded 5 points: 1 point - the surface of the tooth crown is not painted; 2 points $-1 / 4$ of tooth crown surface is painted; 3 points - $1 / 2$ of tooth crown surface is painted; 4 points - $3 / 4$ of the surface of the tooth crown is painted; 5 points - the entire surface of the tooth crown is painted.

To calculate the $\mathrm{OHI}$ the total score for all teeth is divided by the number of teeth examined according to the following formula:

$$
\mathrm{K}=\frac{\mathrm{Kn}}{\mathrm{n}}
$$

where $K_{n}-$ is the sum of all tooth points, $n$ - is the number of teeth (six), $\mathrm{K}$ - is the OHI.

The results determine the level of oral hygiene, namely: (1,1 - 1,5 points - good hygiene); (1.6 - 2.0 points - satisfactory); (2.1 - 2.5 points - unsatisfactory); (2.6 - 3.4 points - bad); (3.5 - 5.0 points - very bad). The OHI is very simple and available; based on this completely objective criterion, the quality and character of oral care can be discussed in different individuals and groups 
of people. Saliva was collected in a glass tube without stimulation, on an empty stomach. The content of cytokines IL-1 $\beta$, IL-10 in saliva was determined by the ELISA kit.

\section{Production of tincture from the GLCE}

To obtain extracts of polyphenols from Legume crop samples, the beans (beans (Phaseolus Vulgaris) “Tirkmela," "Shulavera," "Batumela-mindvris," "Udelebi," green peas (Pisum sativum), lentils (Lens Culinaris), and soybeans (Soybean Glycine max (L)) were crushed into powder, 30 $\mathrm{ml}$ of a water-alcohol solution was added to $1 \mathrm{mg}$ of the powder sample and left for 3 days. The content of polyphenols in the extracts was determined by the Folin-Ciocalteu method; the antiinflammatory, antioxidant, anti-apoptotic activity of the Georgian Legume crops extract (GLCE) was previously evaluated on model cellular systems [5-7].

From lentil (Lens Culinaris) extracts characterized by a particularly high anti-inflammatory, antioxidant, anti-apoptotic activity, a tincture was created for oral cavity rinsing.

For this purpose, dry brown-green lentil seeds $(5 \mathrm{~kg})$ were crushed into small pieces (to $1 \mathrm{ml}$ samples), and then extraction was performed twice with hot water (sample/water ratio 1:10). The extract was filtered through a clean cotton cloth and then through a paper filter. The obtained residue from lentil seeds was kept in a 96\% ethanol solution (residue/solution ratio 1:5) in a large container for 3 days with regular shaking (this process was repeated twice). The extracts were combined, filtered through a paper filter and concentrated using a rotary evaporator at $40^{\circ} \mathrm{C}$. Concentrated water-ethanol extract was used for research.

\section{Statistical analysis}

The statistical analysis of the obtained results, including calculation of means and standard deviations, was conducted using the IBM SPSS Statistics program. The statistical significance of the difference between the means was analyzed by pair-wise comparison of treatment results with nontreated control using Student's $t$-test at $P<0.05$.

\section{RESULTS}

The study was devoted to the comparison of the oral hygiene status (OHI) and severity of the inflammation (the SPT, PMA index) in the patients with deformities of the jaws and teeth using a bracket system under the influence of the standard tincture "Octenidol" (Schulke and MayrGermany) (control group) and tincture made from the GLCE (experimental group) for the mouthwash (during 10 days).

Figure 1 shows that the $\mathrm{OHI}$ in the patients with deformities of the jaws and teeth using a bracket system under the influence of the standard tincture "Octenidol" (Schulke ans Mayr Germany) (control group) did not change significantly (initial - 2,1 $\pm 0,42$ (unsatisfactory), versus, after 10 days $1,6 \pm 0,35$ (satisfactory)). Whereas, in the experimental group under the influence of the tincture made from the Georgian legumes crops extract decreased by $55 \%$ (initial - 2,2 $\pm 0,42$ (unsatisfactory), versus, after 10 days - 1,09 $\pm 0,22$ (good hygiene)). 


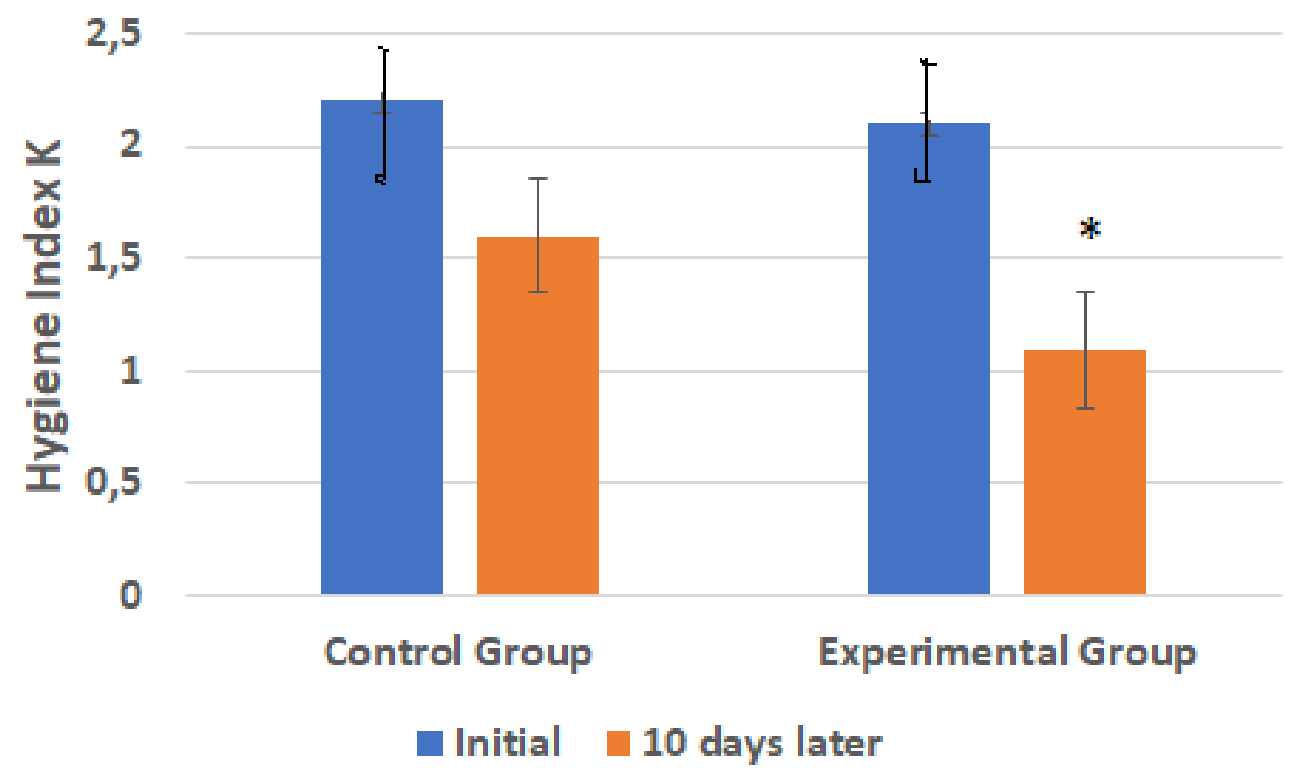

Figure 1. Alterations of $\mathrm{OHI}(\mathrm{K})$ in the patients with deformities of the jaw and teeth using a bracket system under the influence of the standard tincture "Octenidol" (control group) and tincture made from the Georgian legume crop extract (experimental group) (for 10 days). (Mean $\pm \mathrm{SD}$, *statistically significant difference in comparison to the initial level $(P<0.05))$.

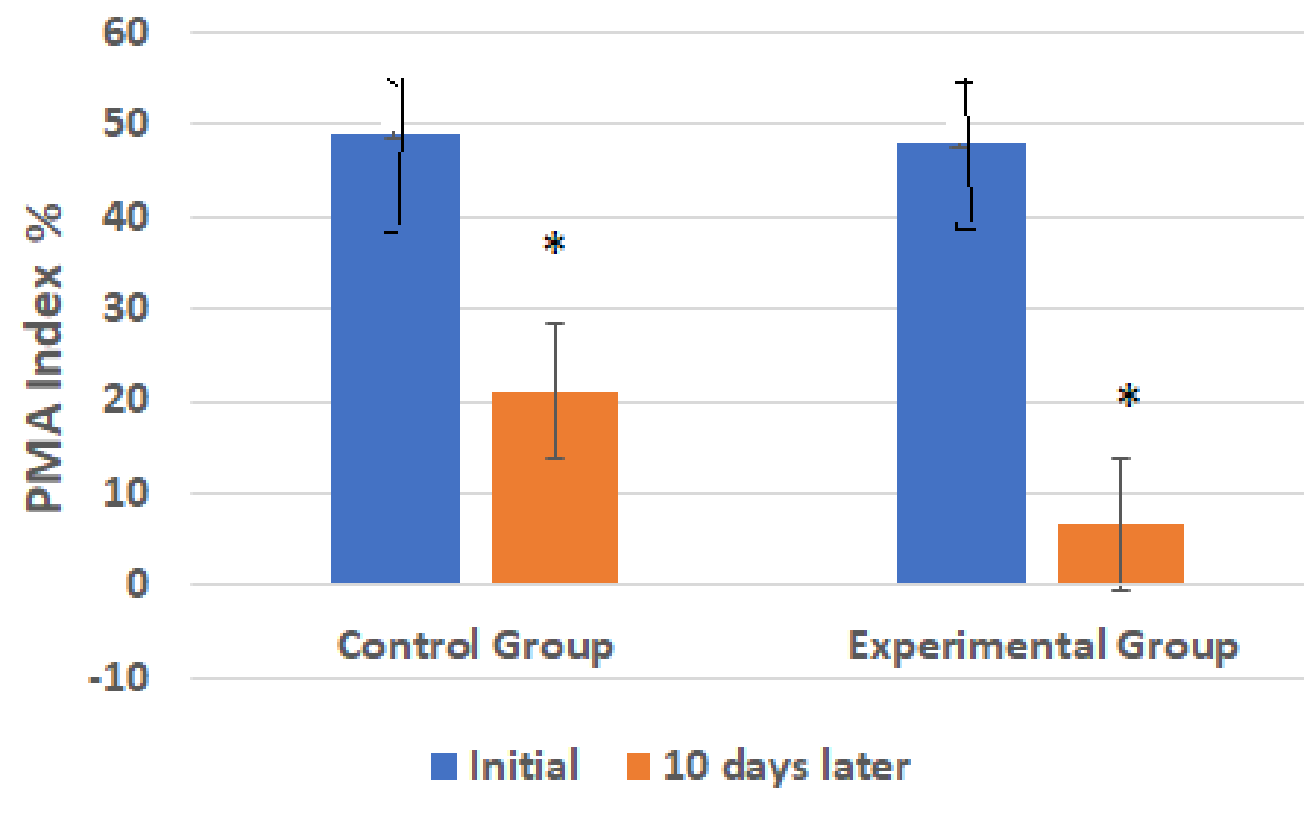

Figure 2. Alterations of PMA index in the patients with deformities of the jaw and teeth using a bracket system under the influence (for 10 days) of the standard tincture "Octenidol" (control group) and tincture made from the GLCE (experimental group) (Mean $\pm \mathrm{SD}$, *- statistically significant difference in comparison to the initial level $(P<0.05))$. 
The mean value of the PMA index in the control and experimental group of patients was (48.9 $\pm 9.2) \%$ (average inflammation) and (47.9 \pm 15.7$) \%$ (average inflammation), respectively. After the use of of the standard tincture mouthwash "Octenidol", the PMA index decreased by $27.8 \%$ (is equal to $(21.1 \pm 9.7) \%$ ) (low inflammation), in the case when the tincture was prepared from the GLCE, decreased by $41.3 \%$ (is equal to $(6.6 \pm 3.5) \%$ ) (negligible inflammation) (Figure 2). PMA index is a measure of the incidence and severity of gingivitis in a given population based on examination and rating of the degree of involvement of the interdental papilla and the marginal and attached portions of the gingiva in each PMA gingival indexes levels are determined by gingival inflammation evaluation items; the higher the number of this index, the more distinct signs of inflammation. Improving oral health and reducing inflammation is usually accompanied by improving oral hygiene and is confirmed by the decline in the index OHI, PMA [25]. We can conclude that the anti-inflammatory effect of the mouthwash tincture prepared from the GLCE has much more potential to prevent generalization of inflammation than the standard one.

Based on the research results, we found that after the standard treatment with tincture "Octenidol" (group I) in 6 out of 14 patients the initial (++) SPT result, indicating on weak inflammation, did not change, in the remaining 8 patients severity of the inflammation decreased from initial serve (+++) SPT result to weak positive (++)) in 3 patients and from initial (++) to $(+)$ (no inflammation) in 5 patients. In the experimental group II, after the treatment with tincture of GLCE, in 8 out of 14 patients initial (++) SPT result indicating weak inflammation, changed to negative $(+)$ (no inflammation) in 7 patients and did not change compared the initial state in 1 patient (remained weak positive (++)); in remaining 6 patients severity of the inflammation decreased from initial serve (+++) SPT result to weak positive (++) in 2 patients, and to negative $(+)$, in 4 patients.

The SPT is based on the detection of glycogen content in the gums, which is strongly increased during inflammation due to keratinization of the epithelium and shows the severity of the inflammatory processes before and after treatment. SPT results enable to evaluate the efficacy of treatment. According to our research results, in the case of medium severity of the inflammation (weak (++) sign) treatment with tincture prepared from the Georgian legume crop extract proved to be more effective in comparison to the standard one (tincture "Octenidol").

The study demonstrated significant positive clinical efficacy of the mouthwash tincture prepared from the GLCE which increases the resistance of dental tissue.

In order to study metabolic indicators of the inflammation in the oral cavity, we examined the content of cytokines (IL-1 $\beta$, IL-10) in the patients' saliva.

Figure 3A shows that the IL-10 content in the saliva of patients with deformities of the jaw and teeth using a bracket system under the influence of the standard tincture "Octenidol" (Schulke and Mayr -Germany) (control group) did not change significantly, whereas in the experimental group under the influence of the tincture made from the Georgian legume crop extract increased $31 \%$. At the same time, the IL-1 $\beta$ content in the saliva of patients with deformities of the jaw and 
teeth using a bracket system did not change significantly in both, control and experimental groups (Figure 3B).

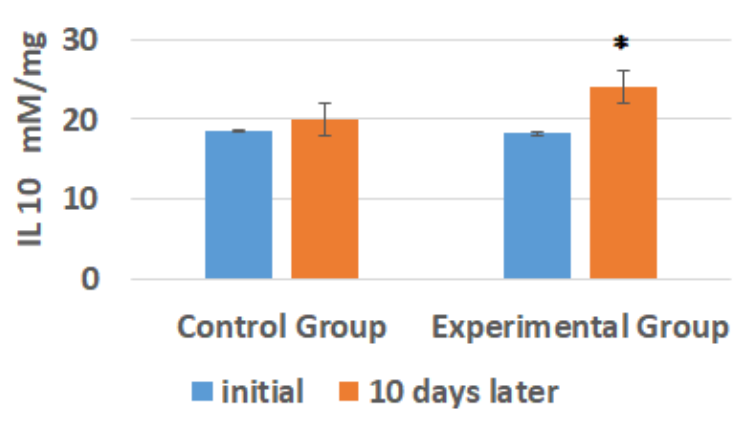

A

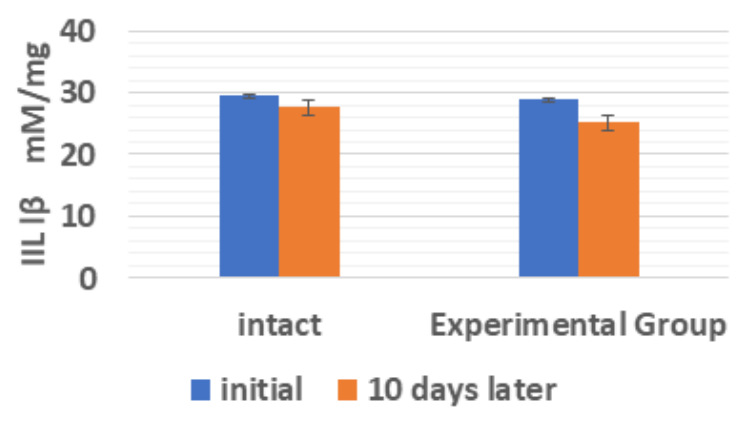

$\mathrm{B}$

Figure 3. Alterations of IL-10 (A) and IL-1 $\beta$ (B) content in the saliva of patients with deformities of the jaws and teeth using a bracket system under the influence (for 10 days) of the standard tincture "Octenidol" (control group) and tincture made from the GLCE (experimental group) (Mean $\pm \mathrm{SD}, *$ - statistically significant difference in comparison to the initial level $(P<0.05)$ )

IL-10 is a cytokine produced by Th-2 cells, B cells, monocytes, and macrophages; IL-10 is involved in the production of $\operatorname{IgA}$, which is the main immunoglobulin in salivary immunity [26]. IL-10 has potent anti-inflammatory actions. IL-10 also has been observed to rise simultaneously with pro-inflammatory markers in the short-term in response to stress and pain [27]. Drug therapies promoting IL-10 are examined to aid in various pain conditions [28].

$\mathrm{IL}-1 \beta$ is a pro-inflammatory cytokine and is produced by macrophages, non-immune cells, and $\mathrm{B}$ and $\mathrm{T}$ cells as part of the innate immune response [29]. It plays an important role in the inflammatory cascade and appears to be a marker of clinical instability [26], also involves pain sensitivity [27, 30, 31, 32].

As follows from the results of the study, patients using tincture prepared from the GLCE had significantly lower values of OHI, PMA index and SPT (compared to patients using the standard tincture "Octenidol" rinse), which indicates increased resistance of soft and hard tissues of the oral cavity. At the same time, these patients showed a statistically significant increase in the content of IL10 in the saliva. IL-10 has potent anti-inflammatory actions, participates in the production of $\operatorname{Ig} \mathrm{A}$, protects against microbes that multiply in the oral cavity, and inhibits the inflammatory effects of other immunoglobulins.

Based on the analysis of the above data, it can be concluded that the tincture prepared from the GLCE stimulates the production of IL-10 by immune cells in the oral cavity and thereby exhibits anti-inflammatory, antimicrobial activity, and increases the resistance of soft tissues of oral cavity against aggressive mechanical pressing. These data indicate the possibility of the development of effective selective dietary supplements based on the GLCE.

Based on the obtained results, we can conclude that the tincture from the GLCE is characterized by a much stronger anti-inflammatory effect than standard tincture "Octenidol" 
(Schulke and Mayr -Germany) used as a mouthwash tincture against inflammation of oral cavity soft tissue. This allows us to recommend the tincture from the GLCE for the treatment and prevention of inflammatory processes in the oral cavity soft tissue.

List of Abbreviations: GLCE, Georgian legume crop extract; SPT, Schiller Pisarev's test; PMA index, Papillary-Marginal Alveolar index; OHI, oral hygiene index.

Competing interests: This study was conducted with research funds under contract with the Ministry of Education, Science, Culture, and Sport of Georgia. Under the Regulations of Bioethics Committee, the research director and the investigators of this study declared necessary conflicts of interest to the ethical review committee.

Authors' Contributions: All authors contributed to this study.

Acknowledgments and Funding: We acknowledge the Ministry of Education, Science, Culture and Sport of Georgia Funds for funding to access the research.

\section{REFERENCES}

1. Gottlieb RA, Nordberg J, Skowronski E, Babior BM: Apoptosis induced in Jurkat cells by several agents is preceded by intracellular acidification. Proc Natl Acad Sci USA 1996, 23; 93(2):654-8.

1. Gonzalez-Segovia R, Quintanar JL, Salinas E, Ceballos-Salazar R, Aviles-Jiménez F, Torres-Lopez J: Effect of the flavonoid quercetin on inflammation and lipid peroxidation induced by Helicobacter pylori in gastric mucosa of guinea pig. J Gastroenterol. 2008, 43(6):441-7.

2. Golusinska-Kardach E, Napierała M, Sokalski J, Kardachi H, Florek E: Periodontal disease in smokers, and the parameters of oxidative stress. Przegl Lek. 2015, 72(10):5847.

3. Nakudashvili Z, Mgebrishvili I, Barbakadze I, Sanikidze T: A Comparative evaluation of the effect of dentures from various materials on the oral cavity's immunological and redoxdependent homeostasis. Georgian Med News. 2018, May;(278):50-55.

4. Ercalik-Yalcinkaya S, Ozcan M: Association between Oral Mucosal Lesions and Hygiene Habits in a Population of Removable Prosthesis Wearers. J Prosthodont2015, 24(4):271278.

5. Galler D, Quiong C, Galler J: A multi-disciplinary approach to congenitally missing anterior teeth. N Y State Dent J. 2009, 75(1):51-3.

6. Kuz VS, Dvornyk VN, Kostenko VA, Kuz GM, Akimov OY: Influence of basic dental materials on indicators of free radical oxidation and antioxidant blood's potential of white rats (experimental study). Wiad Lek. 2018, 71(2 pt 2):318-322. 
7. Moldovan $\mathrm{O}$, Rudolph $\mathrm{H}$, Luthardt RG: Biological complications of removable dental prostheses in the moderately reduced dentition: a systematic literature review. Clin Oral Investig. 2018, 22(7):2439-2461.

8. Mark L. Heaney, Jeffrey R. Gardav Nic, Jeffrey R. Gardner, Nic Golde, David A. Scheinberg: Vitamin $\mathrm{C}$ antagonizes the cytotoxic effects of antineoplastic drugs. Cancer Res. 2008, 68 (19): 8031-8038.

9. Asensi M, Ortega A, Mena S, Feddi F, Estrela JM: Natural polyphenols in cancer therapy. Crit. Rev. Clin. Lab. Sci. 2011, 48: 197-216.

10. Brad A. Sutherland, Rosanna M. Rahman, Ian Appleton: Mechanisms of action of green tea catechins, with a focus on ischemia-induced neurodegeneration. Journal of Nutritional Biochemistry. 2006, 17: 291-306.

11. Gates MA, Tworoger SS, Hecht JL, de Vivo I, Rosner B, Hankinson SE: A prospectivestudy of dietary flavonoid intake and incidence of epithelial ovarian cancer. Int. J. Cancer. 2007, 121: 2225-2232.

12. Hosseinimehr SJ, Mahmoudzadeh A, Ahmadi A, Mohamadifar S, Akhlaghpoor S: Radioprotective effects of hesperidin against genotoxicity induced by gamma-irradiation in human lymphocytes. Mutagenesis. 2009, 24(3):233-5.

13. Chkhikvishvili I, Sanikidze T, Gogia N, Enukidze M, Machavariani M, Kipiani N, Vinokur Y, et al.: Constituents of French Marigold (Tagetes patula L.) Flowers Protect Jurkat TCells against Oxidative Stress. Oxid Med Cell Longev. 2016, 2016:4216285.

14. Chkhikvishvili I, Sanikidze T, Gogia N, Mchedlishvili T, Enukidze M, Machavariani M, Vinokur Y, et al.: Rosmarinic acid-rich extracts of summer savory (Satureja hortensis L.) protect Jurkat T cells against oxidative stress. Oxid Med Cell Longev. 2013:456253.

15. Lursmanashvili L, Gulua L, Turmanidze T, Enukidze M, Machavariani M, Sanikidze T: Biological activity of green tea extracts. Georgian Med News. 2017, 263:88-93.

16. Maminaishvili T, Chkhikvishvili I, Enukidze M, Machavariani M, Kipiani NV, Sanikidze T: Selective efficacy of Georgian legume extracts on Jurkat and MDCK cells. Georgian Med News. 2019, 288:158-162.

17. Reynoso-Camacho R, Ramos-Gomez M, Loarca-Pina G: Bioactive compounds in common bean (Phaseolus vulgaris L.) In: Advances in Agricultural and Food Biotechnology. Edited by Guevara-González RG, Torres-Pacheco I. Signpost: Kerala; 2006: 217-36.

18. Ali NM, Yeap SK, Yusof HM, Beh BK, Ho WY, Koh SP, Abdullah MP, et al.: Comparison of free amino acids, antioxidants, soluble phenolic acids, cytotoxicity and immunomodulation of fermented mung bean and soybean. J Sci Food Agric. 2015, 30;96(5):1648-58.

19. La Marca M, Pucci L, Bollini R, Russo R, Sparvoli F, Gabriele M, Longo V: Antioxidant effect of a fermented powder of Lady Joy bean in primary rat hepatocytes. Cell Mol Biol Lett. 2015; 20:102-16. 
20. Limon RI, Penas E, Torino MI, Martinez-Villaluenga C, Duenas M, Frias J: Fermentation enhances the content of bioactive compounds in kidney bean extracts. Food Chem. 2015; $172: 343-52$.

21. Chkhikvishvili I, Mamniashvili T, Gogia N, Enukidze M, Machavariani M, Sanikidze T: Antioxidant, anti-inflammatory activity of Georgian legumibous crops cultures. S.Georgian Med News. 2017, 272:147-153.

22. Sanikidze TV, Chkhikvishvili ID, Maminaishvili TL, Kipiani Nana V, Enukidze MG, Machavariani MG, Shekiladze ER, et al.: Redox-dependent and independent mechanisms of selective pro-and anti-apoptotic activity of Georgian legumes crops extracts on Jurkat and MDCK cells. Functional Foods in Health and Disease. 2019, 9 (5): 357-370.

23. Svrakov D, Atanasova E: Parodontopatii (etiologiya, klinika i lechenie). Gosudarstvennoe izdatelstvo [Meditsina i fizkultura]; Sofiya,1962: 212. Parma C. Parodontopathy. Leipzig, 1960: 203.

24. Borysenko AV, Vatankha TV: The nearest results of treatment of periodontal diseases in women taking oral contraceptives. Deutscher Wissenschaftsherold. German Science Herald, 2019. 3: 47-50.

25. Stoner L, Lucero AA, Palmer BR, Jones LM, Young JM, Faulkner J: Inflammatory biomarkers for predicting cardiovascular disease. Clinical Biochemistry. 2013.

26. Mika J, Zychowska M, Popiolek-Barczyk K, Rojewska E, Przewlocka B: Importance of glial activation in neuropathic pain. European Journal of Pharmacology. 2013; 716:106119.

27. Shah N, Kammermeier J, Elawad M, Glocker EO: Interleukin-10 and interleukin-10receptor defects in inflammatory bowel disease. Current Allergy and Asthma Reports. 2012; 12:373-379.

28. Dinarello CA: Immunological and inflammatory functions of the interleukin-1 family. Annual Review of Immunology. 2009; 27:519-550.

29. Hutchinson MR, Coats BD, Lewis SS, Zhang Y, Sprunger DB, Rezvani N, Baker EM, et al.: Proinflammatory cytokines oppose opioid-induced acute and chronic analgesia. Brain, Behavior, and Immunity. 2008; 22:1178-1189.

30. Watkins LR, Maier SF: Beyond neurons: Evidence that immune and glial cells contribute to pathological pain states. Physiological Reviews. 2002; 82:981-1011.

31. Holmgren J, Czerkinsky C: Mucosal immunity and vaccines. NatureMedicine. 2005, 11: S45-53. 